\title{
THE BEHAVIOUR OF PENIGILLIN IN SYNOVIAL CAVITIES
}

\author{
G. Blundell Jones, Exeter, England \\ Read at the Spring Meeting of the British Orthopaedic Association, A pril 1947
}

In the treatment of joint infections with penicillin it must be possible to rely upon adequate concentration of the drug within the joint. Rammelkamp and Keefer (1943) suggested that synovial membrane was a barrier to the passage of penicillin from the blood stream. Accordingly the writer investigated the use of local injection into the joint. If penicillin does not get into a joint easily, it should not get out easily, and this proved to be the case in this series.

Table I is a record of twenty-five knee joints in which thirty-two estimations of penicillin concentration were made forty-eight hours after the injection of a single dose of 100,000 units into the joint. Where two values are given, the second was after a further injection at a later date when no penicillin remained in the joint from the first injection. All these joints had open war wounds. At the original operation the synovial membrane alone was closed by interrupted suture; the wound itself and secondary incisions were left open. The operation was completed by the injection of 100,000 units of penicillin into the joint cavity in 5-10 c.c. fluid. The limbs were then immobilised in Thomas knee splints, with light traction, and plaster of Paris of a modified "Tobruk" type, leaving the knee joint exposed.

Penicillin estimations were made by the crude cup method against the standard Oxford $\mathrm{H}$ strain of staphylococcus aureus, using a single drop of synovial fluid in one cup, and a similar drop of calcium-penicillin solution 100 units per c.c. in another cup as control. The figures given in the second and third columns refer to the radius, in millimetres, of the zone of inhibition of growth of organisms round the cups after incubation. This method should be quite accurate for our purpose which is to recognise only a bacteriostatic concentration in the fluid. Any value above 0 is therefore satisfactory. No penicillin was given by other routes in any of these cases.

Penicillin is still present in adequate concentration in twenty-four of the thirty-two estimations. Table II shows that, sometimes at least, it can be found as long as eighty-four hours after injection (Case 16). What are the factors which govern the length of time penicillin persists? First one would think that in joints with marked bone damage the drug would leak into surrounding tissues, or be absorbed rapidly from raw bone surfaces. I have indicated in the chart the severity of bone damage from 0 to,+++ 0 indicating only slight cartilage injury and +++ extensive shattering with fractures extending into the bone shaft. It will be seen readily that there is no relationship between the extent of damage and the persistence of penicillin (note especially Case 19 in Table II with most severe damage and yet effective penicillin concentration after seventy-two hours; and Cases $29 \mathrm{~A}$ and $31 \mathrm{~A}$ with no bone injury and yet with negative values at forty-eight hours). It is to be presumed that the sealing off by clot and haematoma effectively prevents absorption. This observation may also be true in wounds of soft tissues.

An observation which I think is of some importance is the variation of penicillin concentration according to the "tidal " behaviour of the joint. When the tide is coming into the joint in the form of increasing effusion, penicillin always persists for over forty-eight hours, and has been recorded up to eighty-four hours in adequate concentration. (Case 16, Table II). When the tide is going out, and the joint is actively absorbing effusion, we find that the penicillin goes with it and does not last even for forty-eight hours. This tide is indicated in the chart by 0 when it is coming in or stationary, \pm when it is beginning to turn, and + when it is going out and the joint is actively absorbing effusion. In every case in which no effective penicillin was found after forty-eight hours, the joint was always absorbing effusion actively. This observation is particularly notable in Cases $25,30,31$, and 34 , where two estimations were made at different stages. 
TABLE I

Estimations of Penicillin Concentrations in 25 Knee Joints 48 hours after intra-articular injection of 100,000 units

\begin{tabular}{|c|c|c|c|c|}
\hline Case number & $\begin{array}{c}\text { 1'Assay of } \\
\text { synovial fluid }\end{array}$ & ${ }^{1}$ Control & $\begin{array}{c}2 \text { Degree of } \\
\text { bone injury }\end{array}$ & $\begin{array}{l}{ }^{3} \text { Clinical absorption } \\
\text { phase of joint }\end{array}$ \\
\hline 7 & 10 & 14 & 0 & 0 \\
\hline 8 & 20 & 20 & + & 0 \\
\hline 16 & 3 & 13 & 0 & 0 \\
\hline 19 & $3 \cdot 5$ & 12 & +++ & 0 \\
\hline 20 & 2 (60 hrs.) & 14 & ++ & 0 \\
\hline 23 & $2 \cdot 5$ & 13 & ++ & 0 \\
\hline 24 & 1 & 11 & 0 & \pm \\
\hline 25 & $\begin{array}{l}4 \\
0 \\
\end{array}$ & $\begin{array}{l}13 \\
14 \\
\end{array}$ & + & $\begin{array}{r}0 \\
+ \\
\end{array}$ \\
\hline 27 & 0 & 13 & 0 & + \\
\hline 28 & 5 & 14 & + & 0 \\
\hline 29 & 6 & 14 & + & 0 \\
\hline $29 A$ & 0 & 14 & 0 & + \\
\hline $29 B$ & 8 & 14 & + & \pm \\
\hline 30 & $\begin{array}{l}8 \\
0\end{array}$ & $\begin{array}{l}14 \\
14 \\
\end{array}$ & ++ & $\begin{array}{l}0 \\
+ \\
\end{array}$ \\
\hline $30 \mathrm{~A}$ & 4 & 13 & 0 & 0 \\
\hline $30 \mathrm{~B}$ & $2 \cdot 5$ & 13 & 0 & 0 \\
\hline 31 & $\begin{array}{l}\mathbf{5} \\
\mathbf{3} \\
\end{array}$ & $\begin{array}{l}13 \\
13 \\
\end{array}$ & $+t+$ & $\begin{array}{l}0 \\
\pm \\
\end{array}$ \\
\hline $31 \mathrm{~A}$ & 0 & 13 & 0 & + \\
\hline 32 & $\begin{array}{l}0 \\
0\end{array}$ & $\begin{array}{l}14 \\
14 \\
\end{array}$ & ++ & \pm \\
\hline $32 \mathrm{~A}$ & 6 & 14 & 0 & 0 \\
\hline 33 & $\begin{array}{l}4 \cdot 5 \\
5\end{array}$ & $\begin{array}{l}13 \\
13 \\
\end{array}$ & + & $\begin{array}{l}0 \\
0\end{array}$ \\
\hline 34 & $\begin{array}{l}5 \\
0\end{array}$ & $\begin{array}{l}12 \\
12 \\
\end{array}$ & ++ & $\begin{array}{l}0 \\
+ \\
\end{array}$ \\
\hline 35 & $\begin{array}{l}5 \\
3 \\
\end{array}$ & $\begin{array}{l}13 \\
13 \\
\end{array}$ & 0 & $\begin{array}{l}0 \\
0 \\
\end{array}$ \\
\hline 37 & 7 & 14 & $++t$ & 0 \\
\hline 38 & 2 & 14 & 0 & \pm \\
\hline
\end{tabular}

1 Assay of synovial fluid and Control-Figures indicate radius in millimetres, of zone of inhibition of growth of micro-organisms after incubation.

2 Severity of bone injury-Indicated in degrees from 0 (slight injury to articular cartilage) to +++ (extensive shattering of bone).

3 Clinical absorption phase-No absorption (effusion increasing) 0. Beginning absorption of effusion \pm . Active absorption of effusion + . 
A joint which is in this absorptive stage, with " the tide going out," is recovering and probably does not need the protection of penicillin. It is believed, therefore, that the intraarticular injection of 100,000 units effectively protects the joint for forty-eight hours. In fact the author has treated forty cases of open war wounds of the knee joint by repeated forty-eight hourly injections without any other penicillin administration and there has been no case of joint injection(JonEs, G. Blundell 1945). Therein lies the proof. Local injection is the only way, as well as the easiest way, of ensuring proper concentration of penicillin within a joint. Furthermore, a high level of concentration may be achieved if it is necessary to deal with micro-organisms which are sensitive only to much higher concentrations than the Oxford staphylococcus.

Actually, later reports have shown that penicillin does get into joints when given by intramuscular injection, but it would appear that the concentration in synovial fluid is less than in the blood. (Hughes 1945, Bonnin and Prior 1945, Simmonds, Jenkins, and McKenzie 1945, Foster and Colquhoun 1945.) Unfortunately these investigators reported only cases of traumatic synovitis. Moreover, they did not immobilise the joints strictly and we know, from the work of Bauer and others, that mobility profoundly influences the rate of absorption from joints. Six cases were investigated in which general penicillin therapy was

TABLE II

Estimation of Penicillin Concentration in Three Knee Joints at 12-Hourly Intervals up to 96 Hours

after intra-articular injection of 100,000 units

\begin{tabular}{|c|c|c|c|c|c|c|c|c|c|}
\hline \multirow{2}{*}{ Case } & \multicolumn{8}{|c|}{ Hours } & \multirow{2}{*}{$\begin{array}{l}\text { Severity of } \\
\text { bone injury }\end{array}$} \\
\hline & 12 & 24 & 36 & 48 & 60 & 72 & 84 & 96 & \\
\hline 16 & + & 7 & + & 3 & 1.5 & 5 & 1 & 0 & 0 \\
\hline 19 & 11 & 6 & 7 & $3 \cdot 5$ & 4 & 2 & 0 & 0 & +++ \\
\hline 20 & + & + & + & + & 2 & 1.5 & 0 & 0 & 0 \\
\hline
\end{tabular}

maintained by intra-muscular injection, but with no intra-articular injection, and in which complete immobilisation of the knee joint was maintained as in all other cases in this study. After two days of 100,000 units per day by continuous intramuscular drip none of these showed bacteriostasis when a drop of fluid from the knee joint was assayed by the method described. Thus, I believe that parenteral penicillin should be used in joint infections only as an aid to local use when other considerations demand it.

The technique of local administration used in this series was to inject 100,000 units into the joint; to repeat the injection every forty-eight hours, with aspiration of the joint, until effusion was subsiding (usually from three to five aspirations); then to omit one injection; and finally to give one more injection forty-eight hours later. With the dose dissolved in 5 to 10 c.c. of fluid no joint irritation was produced, although the injection was occasionally painful for a few minutes afterwards.

In the series of forty war wounds of the knee joint only the synovial membrane was closed in the first instance. If complete primary closure is practised, the use of parenteral penicillin, in addition to penicillin sulphathiazole powder in the wound, is to be recommended. However, the results of delayed primary suture are so satisfactory that it is doubtful whether complete primary suture is ever justifiable.

Where joint infection arises as part of a general blood-stream spread parenteral penicillin should obviously be used in dosage adequate for the micro-organism concerned. 
SUMMARY

1. The behaviour of penicillin injected locally into knee joints is investigated and found to be the only satisfactory way of using the drug in joint wounds and infections.

2. Penicillin persists within the joint for forty-eight hours after injection unless the effusion is being actively absorbed.

3. The additional administration of penicillin by intramuscular injection is recommended when other considerations demand it.

I am indebted to Dr G. B. Forbes, Pathologist, for the penicillin estimations, often carried out at inconvenient hours and under field conditions.

\section{REFERENCES}

Bonnin, J. G., and Prior, A. P. (1945): Penicillin Therapy and Control in 21 Army Group, 335.

Foster, J. N., and Colquhoun, J. (1945): Penicillin Therapy and Control in 21 Army Group, 339.

Hughes, K. E. A. (1945): Penicillin Therapy and Control in 21 Army Group, 333.

Jones, G. Blundell (1945): Penicillin Therapy and Control in 21 Army Group, 167.

RAmmelkamp, C. H., and KeEFeR, C. S. (1943): Journal of Clinical Investigation, $22,425$.

Simmonds, F. A., Jenkins, T. P. N., and Mackenzie, R. D. (1945): Penicillin Therapy and Control in 21 Army Group, 345. 